\title{
A letter to a friend: Artificial intelligence and intelligent artifacts
}

\author{
ELLEN YI-LUEN DO \\ College of Architecture and College of Computing, Georgia Institute of Technology, Atlanta, Georgia, USA
}

\section{Dear AI EDAM,} I am very happy that we will be celebrating your 25th birthday this year. Perhaps a coming of age celebration is in order? David and Yan said that we should all say something for this occasion, so I am writing you a personal note.

Alan Kay was quoted as saying that the best way to predict the future is to invent it. Meanwhile, ideas, innovations, and inventions all need a forum to strive. You have, in your quiet manner, provided a nice venue for researchers, both novice and seasoned, to present and exchange ideas. Kudos to you!

You have a broad range of interests and have hosted a wide variety of interesting research endeavors in your portfolio. As I reflect on all our joint adventures in the past decade, I am happy to say that it has been a fun and exciting journey and a personal and meaningful one. The "Drawing Marks, Acts and Reacts" article [16(3), 2002] in the Special Issue on Human-Computer Interaction in Engineering Contexts presented my work in sketch computing to support design by providing appropriate knowledge-based tools at the right time. Claudia Eckert and I put together the Special Issue on Understanding, Representing, and Reasoning about Style [20(3), 2006] with articles on methods, analysis, and applications for design in products, vehicles, and architecture. Mark Gross and I created the Back to the Real World: Tangible Interaction for Design [23(2), 2009] Special Issue to introduce your readers to the growing field of coupling digital information to physical representations that are mediated by human senses, leveraging the affordances of things and control mechanisms. Last year, Ashok Goel and I filled our Special Issue on Design Computing and Cognition [24(1), 2010] with articles addressing three sources for design research: design computing, design cognition, and human-centered information technology. People are increasingly developing artificial intelligence as well as intelligent artifacts.

If we consider artificial intelligence as the science and engineering of making intelligent machines with intelligent programs, the challenges ahead of us would be both on the understanding of human intelligence and on providing methods and insights to help implement the computational abilities into physical reality to achieve goals in the world. This is no easy task. In the upcoming 10 years I would expect you to take things in stride by continuing to provide forums for researchers to share ideas and discoveries about artificial intelligence in engineering design, analysis, and manufacturing and perhaps addressing the universe of all scales as depicted in the movie Powers of Ten toward realizations of Star Trek gadgetries, mythical and magical Hogwarts, and nurturing next generation modern day Leonardo da Vincis?

May the Force be with you!
Reprint requests to: Ellen Yi-Luen Do, College of Architecture \& College of Computing, Georgia Institute of Technology, Health Systems Institute 210B, Atlanta, GA 30308, USA. E-mail: ellendo@gatech.edu 